\title{
PSYCHIATRY IN TIME OF COVID-19 PANDEMIC
}

\author{
Carlo Lazzari $^{1,4}$, Ahmed Shoka ${ }^{2,4}$, Abdul Nusair ${ }^{1,4}$ \& Marco Rabottini ${ }^{3,4}$ \\ ${ }^{I}$ South-West Yorkshire NHS Trust, Fieldhead Hospital, Wakefield, United Kingdom \\ ${ }^{2}$ Essex Partnership University Foundation NHS Trust, The King's Wood Centre, Colchester, United Kingdom \\ ${ }^{3}$ International Centre for Healthcare and Medical Education, Bristol, United Kingdom \\ ${ }^{4}$ Steering Committee for the Study of COVID-19 Psychiatry, London, United Kingdom
}

received: 20.4.2020;

revised: 11.5.2020;

accepted: 25.5.2020

\section{SUMMARY}

COVID-19 or Coronavirus pandemic has generated a very serious and grave global concern regarding the health of every person in the whole world. Besides, due to the rapid diffusion of the viral infection, there are already alarms on how to deal with the psychiatric aspects of COVID-19 pandemic in persons with an established diagnosis of psychiatric disorders, staff, and those in selfisolation. What is the influence of COVID-19 on mental health? The current study will review the psychiatric implications of COVID-19 pandemic on the general population, the bearing of social isolation, the prevention behaviours, and clinical cases of people who required psychiatric admission to hospital due to the emotional impact of COVID-19 social circumstances.

Key words: COVID-19 - Coronavirus - psychiatry - isolation - suicide - psychosis - health behaviour

$$
* * * * *
$$

\section{INTRODUCTION}

Any plague of pandemic dimension has human, psychological, legal and behavioural consequences on the whole population. The day we started to write this paper, $12^{\text {th }}$ of April 2020 there were about 133,495 cases of confirmed COVID-19 infection in the United Kingdom (UK) with 18,100 deaths in increase and $2,628,527$ cases in the whole world with more than 183,424 deaths (Public Health England 2020). It is not only the agony, sorrow, and many unexpected deaths that make the public so anxious in an epidemic, but also the associated interruption of civilisation, particularly as the food source often become scarce, the survivors cannot manage with burying the deceased and witnessing those who can escape quick and distant (Cunningham 2008). The rapid diffusion of Coronavirus or COVID-19 in the current century is creating concerns also in the psychiatric services for the direct and indirect impact of the pandemic on the whole population and individuals with mental health conditions.

In another group of patients, the underlying healthbehaviours might reduce the cognitive schema to stay healthy, to consider the well-being of others and to minimise risks to self (Lazzari \& Masino 2015). In those persons, it will be difficult to teach any information regarding COVID-19 prevention, and therefore, these persons should be considered as large spreaders of COVID-19. Similarly, patients with established enduring mental illnesses might have difficulty to grasp the basic concepts of the disease, the principles of selfpreservation and vulnerability to any other conditions. In these cases, underlying beliefs, delusions or behaviours do not allow the whole grasp of what Coronavirus means in terms of impact on their own lives.

\section{PSYCHIATRY DURING COVID-19 PANDEMIC}

Although the average population will show normal responses to pandemic stressors, others more mentally vulnerable to anxiety will have overstated emotional responses. Catastrophic thinking can trigger a series of emotional reactions in the healthy population such as 1) panic disorder with anxiety about medical, psychological and social disasters; 2) specific phobias, for instance, illness phobia or rupophobia (fear of dirt); 3) obsessivecompulsive disorder, for example, obsessive ruminations about being contaminated by COVID-19 or obsessive washing and cleaning; 4) post-traumatic stress disorder, for instance, those who survived severe health conditions or have enduring physical illnesses might recall their past suffering and relapse in severe anxiety believing that during COVID-19 they might renew severe distress; 5) pain, for example, persons who have a low threshold for pain might anticipate possible COVID-19 infection as an intolerable condition (Gellatly \& Beck 2016). There will likely be a reduced number of mental-health professionals and experienced psychologist to offer face-to-face psychological support both on the territory and in psychiatric wards (Duan \& Zhu 2020). Similarly, particular consideration should be given to psychiatric personnel offering service in institutions at risk (e.g., prisons) who should be alerted about the potential risk of becoming infected by COVID-19 themselves due to advanced age or any underlying medical conditions such as chronic respiratory disease, diabetes, hypertension, immunodeficiency, and others (Liebrenz et al. 2020).

In other instances, the emotional load linked to severe and lethal illnesses like COVID-19 pandemic can affect vulnerable people beyond their point of resistance, 
leading to increased stress reactions, depression, suicide, homicide, and psychosis. It is reported that in some part of the world, the population started to discriminate against Asian people and declined sitting next to them on buses or trains or directly criticised them on social media up to physical assault (Ho et al. 2020).

In other cases, people might become vulnerable to COVID-19 infection only by disregarding prevention. For instance, those with mild learning disabilities living alone in the community might not attend to the aspects of COVID-19. Others, like those with dissocial personality disorder and paranoias are chronically intolerant of restrictions and regulations, hence missing essential messages about keeping self and others safe. Two major psychiatric illness can put other at risk of COVID-19 infection. Persons with a dissocial personality disorder, the show an uncaring indifference about the state of mind of other people, and a total and obstinate attitude of recklessness and disrespect for societal rules and duties (World Health Organization 2020). Therefore, these people are unlikely to follow recommendations for protecting others from Coronavirus contagion, although aware of consequences.

Similarly, those with paranoid personality disorder are always suspicious and have a prevalent inclination to misinterpret knowledge and misconstruct the unbiased and welcoming activities of others as unfriendly or disapproving (World Health Organization 2020). Therefore, paranoid persons will deem as false, questionable or fake official health information regarding Coronavirus protection, while feeling targeted by health authorities or anyone who will address their reckless disregard of social distances and warnings about COVID-19 protections. However, paranoia could act in both directions, either in underestimating or overestimating the risk of contagion with COVID-19. In the last case, one should expect more isolation and behaviours aiming to limit contacts with others. A tripartite cognitive model of paranoia suggests that symptoms originate from atypical understandings of reality, combined with emotional depression, anxiety, increased self-absorption, and social distrust (Sen \& Chowdhury 2006).

Overall, stressful life events will trigger psychiatric illness for the first time or relapses in those who already have an enduring mental illness. Several traumatic life events and disasters can trigger psychiatric disease for the first time in predisposed persons or cause a relapse in those who already have enduring mental illness including schizophrenia, depression and neurosis (Andrews $\&$ Tennant 1978). Stressful life events have been reported as producing increased relative risk for schizophrenia, suicide and depression (Paykel 1978). Also in the healthy population, natural or man-caused calamities can increase vulnerability to anxiety and maladaptive behaviours but mostly raising personal feelings of vulnerability especially after the death of beloved persons, loss of financial assets, direct or indirect damage to possessions, disruption of emotional attachments, forced separation from close family members and altered feelings of roles in the society (Makwana 2019).
The COVID-19 is also impacting on the mental health of healthcare professionals who are in the forefront in dealing directly with patients at risk or already infected while coping with an increased workload, reduction of PPE (Personal Protection Equipment), lack of specific treatment, and feeling insufficient support; all these factors increase depression, anxiety, insomnia and level of personal distress (Lai et al. 2019).

\section{PSYCHIATRIC IMPACT OF SELF-ISOLATION}

Self-isolation is the process of reducing or stopping social contacts and activities in order to decrease the likelihood chance of being infected or when having symptoms of minor infections like influenza or respiratory symptoms which suggest that caution should be taken for the protection of others. In other countries, like Italy and United Kingdom, there have been strict regulations for the population not to come out of their houses to reduce the escalating number of infected cases, while the army and the police are enforcing the quarantine of the whole inhabitants. In these circumstances, although home-work and telework have been implemented, a person stops directly interacting with others. Self-isolation is the only effective control for the eruption of COVID-19 pandemic and to avoid the interruption of admissions to hospital beds in intensive care (Grasselli 2020).

Similarly, unless the storage of food and other necessities has already occurred, there are significant difficulties in everyday life. Likewise, confined restriction without any chance to open the main door has enormous consequences on mental health conditions. At the same time, the distress of being self-limited is an unprecedented situation in the current century. One of the most affected groups of the population are older adults who cannot benefit from online psychiatric consultations due to lack of internet and smartphone skills, while their carers will have to restrict the frequency of home visits; this occurrence will worsen existing psychiatric conditions (Yang et al. 2020). Likewise, isolation forces reduction of exposure to natural light increasing vitamin D deficiency accounting for the outbreak of increased mental disorders due to reduced contact with the sunlight (UV-B) (Humble 2010).

The process of self-isolation can itself increase the level of anxiety, apprehension and stress. There might be a tendency to start having ruminating obsessional thoughts and hypochondriac or phobic fears. One will need to be also aware of the increase in the level of frustration, anger and relationship difficulties within families or households. Factors that buffer mental disorders are social cohesion and support from neighbours who are deficient during social isolation (Gyasi et al. 2017).

The irony of this distressing situation is that in normal circumstances, sick individuals will be waiting in anticipation to get better; but in this current global crisis, healthy individuals are waiting in anticipation to become ill or infected with COVID-19; so, the balance is upside down or shifted by 180 degrees. 
A series of biases might also impact on prevention behaviour of some healthcare professionals who might feel protected from contagion just by having 'enough' information about COVID-19 and its routes of transmission. In places where the outbreak of infection has been massive, people in quarantine in their house experience boredom, isolation and resentment; in more severe cases it has been reported depression, panic attacks, or suicidality (Xiang et al. 2020). It is predicted that social isolation will have an enormous impact on the elderly living alone who, with physical separation from any social bonds, will experience an increased vulnerability to physical and mental illnesses, including dementia (Courtin \& Knapp 2015). Besides, social isolation in the elderly will reduce their access to community resources and care, contact to social support and physical care hence adding physical health risks to feelings of loneliness and isolation (Armitage \& Nellums 2020).

\section{COVID-19, SUICIDE AND HOMICIDE}

The pandemic aspects of COVID-19 could affect people directly and indirectly by creating levels of concerns beyond the point of personal resistance. There are already accounts of people infected or not who have chosen the way of suicide to cope with the idea of being infected, of infecting others or seeing close family members being affected. The typology could be divided into the following category. In the altruist suicide, a person chooses to take her or his own life in the attempt not cause unnecessary harm to other family members. This presentation is the case of the 34-year old Italian nurse who, after resulting COVID-19 positive, decided to take her life not to infect other family members (Alarabiya 2020). A 50-year older adult man from Andhra Pradesh, India, committed suicide fearing that he would also infect his family because he misunderstood a doctor's request to wear a mask as a sign of being COVID-19 positive (Report 2020). More apocalyptic conditions occur with mass suicide during and around catastrophic events or simple predictions, although not seen in the current pandemic but could explain some of the behaviours of mercy killing. Mass suicide has been divided in directed towards others as a way to avoid a condition that does not recognise their human goodness and towards the self when several persons are trying to escape from an unbearable situation due to misinterpretation of reality (Mancinelli et al. 2002). Another aspect, as occurred during the HIV epidemic, is that people with suicidal ideation might unconsciously or deliberately pursue a lethal infection to commit suicide (Lazzari et al. 1994). The Syndrome of Samos indicates the behaviour of some HIV-negative people mostly with a borderline personality disorder of having unprotected sexual relationships with persons with AIDS to 'share destiny and life' (Lazzari et al. 1994, Lazzari 2013). The prediction is that people with morbid suicidal ideation or borderline personality disorder might ignore COVID-19 prevention as a way of acting on their suicidal ideation. In a Danish study, infections and their direct neuroinflammatory effects have been found directly correlated to increased risk suicide such as during HIV infection, Hepatitis C, Influenza B, Coronaviruses, Toxoplasma Gondii and Cytomegalovirus (Brundin 2016, Torjesen 2016).

A more extreme case of paranoia is that of the Italian male nurse who strangled to death his doctor girlfriend believing that she gave him Coronavirus (Tidman 2020). When referring to homicide or attempted homicide, the current article reports the case of a man who was admitted to a psychiatric hospital after he disclosed planning a homicide-suicide by using an axe to kill his family and then himself in an attempt to escape from COVID-19 threat. Homicide-suicide is a separate entity and is usually performed by a man over a spouse or other members of the family by using firearms (Saleva 2007). In the case of filicide-suicide, the literature reports the prevalence of schizoid personality disorder, which has the most definite link with violent crimes more than antisocial and borderline personality disorder (Declercq 2016).

\section{COVID-19, NEUROINFLAMMATION AND PSYCHOSES}

More direct associations between psychiatric illness and infectious diseases are reported in the literature. For instance, there are studies about the possible association of generalised infections and brain inflammation conducive to psychosis or later development of Alzheimer in the vulnerable population (Kinney et al. 2018, Lazzari et al. 2019) depression, mania and psychosis associated to HIV infection (Perry \& Jacobsen 1986), psychosis linked to Dengue (Blum 2010), and an increase of schizophrenia and other psychoses following influenza pandemics (Kępińska 2020). There are not yet reports about the direct implication of COVID-19 in organic psychosis and mood disorder, while this perspective is only speculative.

\section{COVID-19 IMPACT ON PSYCHIATRIC CARE}

General concerns exist in psychiatric or general wards when patients with possible COVID-19 are admitted into hospitals. In fact, due to the difficulty of management of patients in restricted or open psychiatric wards, a whole array of behaviours can put these patients and their carers at risk of COVID-19 infection. If a patient is at risk and has been admitted into an intensive care unit in a hospital, risks exist in managing both the viral infection and the psychiatric presentation.

Similarly, staff who attend to those patients will be at high risk as some of the behaviours of disturbed patients may not stop at being mindful not to spread the infection of COVID-19, but they can also physically assault staff. Patients might need seclusion while the team is at risk of proximity physical contact with those patients and their bodily secretions. Other times, some patients are admitted to psychiatric hospitals with their 
health behaviour being unknown. Hence, they might already have been at risk but have not self-isolated or have been in contact with persons at risk but not aware that they should disclose it.

At the same time, psychiatric inpatients that are allowed or granted leave into the local community might enter into the risk zone of contagions and then return to the ward after they have been exposed to the COVID-19 while being unaware of this. Similarly, psychiatric wards have frequent visits from family and relatives of patients, and these persons too might be at risk of carrying the COVID-19 into psychiatric wards. The same should be said about patients who attend community psychiatricteam meetings, group therapy and appointments, hence posing a risk to all the mental-health professionals who conduct or facilitate these clinical activities.

There is an emotional impact of COVID-19 among medics who are doing home assessments to section a patient according to the UK Mental Health Act, 1983. These professionals might be exposed to COVID-19 contagion due to entering into settings without adequate Personal Protective Equipment (PPE), or some of these psychiatric patients who are being assessed might already have been contagious. In general, health care professionals have been found suffering from frustration due to lack of protection from COVID-19, increased workload, prejudice from other professionals, feelings of isolation, and tiredness (Kang et al. 2020).

During current COVID-19 pandemics, there are already significant changes and challenges to psychiatric routines. For instance, teams start to use video consultations for reduction of risk to staff deriving from behavioural dysregulation of patients who have Coronavirus or are deemed to be infected, although teams are challenged by the care of those who are homeless and more at risk of being in contact with sources of infections or by others who need constant support from carers and are thus unable to maintain social distances (Shalev \& Shapiro 2020). COVID-19 pandemics is already changing the definition of risk to self and others posed by patients in the tenant of the Mental Health Act (1983) in the UK. Some tribunals for the psychiatric patients (in the UK, patients have the right to appeal against their compulsory admissions to a hospital) already accept COVID-19 in the definition of risk and that a patient might be at risk for self and others if not using virus protection. Guided by the Human Rights Act 1888, each person has the following rights, 1) Article 2: the right to life, and 2) Article 5: the right to liberty and security including the legal detention of a person for the prevention of the diffusion of an infection (Zigmond \& Brindle 2016).

Therefore, a person who neglects the use of proper COVID-19 PPE while in a public place and aware that he or she might put others at risk for their life and security is potentially trespassing the Human Rights Acts 1988. In the case this person lacks capacity and insight and suffers from enduring mental illness, his or her behaviours might endanger self or others for COVID-19 infection and might be considered risks for health, self and others especially if the patient is already COVID-19 positive. In the Mantel Health Act (1983) statutory conditions for discharge of a psychiatric patient to community stand, 1) the degree of injures to which others are exposed if a patient is discharged from the psychiatric hospital; 2) that the patient remains in the hospital for the own safety and health and the protection of others (Zigmond \& Brindle 2016). Other consequences of COVID-19 impact on psychiatric wards are reduced beds for inpatients, narrowed accessibility to therapeutic resources and leisure, increased physical and technical limitations of patients activities to counterbalance reduced social distance, reduced contacts with families and community agencies, and restricted or absent community leave (Royal College of Psychiatrists 2020).

\section{HEALTH PROTECTION BEHAVIOURS}

A series of behaviours are found during transmittable diseases where the conducts of each person are conducive or not to the prevention of illness in the self and others. A series of personal biases can impact on the adherence or not to actions to avoid transmittable diseases. One of the forms that produced an outbreak of HIV diffusion was the finding that some people cognitively separated the knowing what and knowing how from believing what and believing how (Lazzari \& Costigliola 1993). During the HIV epidemics, many people knew what a contagious infection was and what the routes of transmission were; however, some believed that the full information about the way of infection or impact was inaccurate. Instead, they compartmentalised the information accepting only parts of it, and thinking for instance, 'viral infections only affect debilitated people,' or 'infectious illnesses affect only those who are at high risk' (Lazzari et al. 1996).

The proclivity to generate self-reassuring information was also generalised as a denial not to incorporate the truth of the whole data. Sometimes, even those who accept the fact about contagious illnesses externalise the responsibilities assuming that it is someone else's obligation to impede the diffusion of viruses. Those with the psychological dimension of external locus of control will likely put efforts or responsibilities on others to reduce or avoid infections in the self.

Health behaviours respond to two major theoretical frameworks: the Social Learning Theory (SLT) and the Health Belief Model (HBM) (Rosenstock 1988). The SLT is linked to 1) anticipations about environment and views about how actions are connected (e.g. how the COVID-19 pandemic will affect self as a consequence of the own lifestyle); 2) predictions about the outcomes of the own behaviours (e.g., how COVID-19 risk is linked to the own daily actions); 3) beliefs about the own skills to complete the steps desirable to achieve the outcomes (e.g. how the use of PPE will reduce the risk of COVID-19 contagion) (Rosenstock 1988). The HBM is linked to 1) estimated vulnerability to a threat of an illness and its effects (e.g. perceived vulnerability to 
COVID-19 infection); 2) valued advantages of performing specific behaviours minus the losses or obstacles to a targeted accomplishment (e.g. the benefits or costs of working at home during the current pandemic); 3) importance in lessening alleged risks (e.g., personal advantages or disadvantages to quarantine in the own house) (Rosenstock 1988). It is also perceived that those who have not started to take precautions for autologous (infection of the self) and heterologous (contagion of others) precautions might not have progressed from Prochaska \& DiClemente stage of Precontemplation (acknowledging no need for viral protections) to the conclusive stage(s) of Action (assuming new behaviours) and Maintenance (practising better performances) (Prochaska \& DiClemente 1982).

\section{SOME CLINICAL CASES}

The presentations of the clinical cases found in our practice support the hypothesis that COVID-19 pandemic can trigger, exacerbate or deteriorate psychiatric symptoms in relatively stable people who never had contacts with psychiatric services before. In all cases, psychiatric symptoms are usually accompanied by severe anxiety which is in a direct or indirect way linked to COVID-19 pandemic, social isolation, limitations or interruption of daily activities. In one case, the COVID19 pandemic was incorporated into a delusional belief of government 'experimentation' to the point to generate a severe first-presentation psychotic symptom. In this case, COVID-19 emotional impact could have triggered a dormant paranoid psychosis. Research reports that stress can increase dopamine levels in the brain, causing psychosis hence postulating the role of psychological stress to trigger psychosis in vulnerable persons (Soliman 2007). In another person, a severe stress reaction determined by self-isolation caused severe anxiety, depression and suspiciousness. A feeling of guilt ensued as a consequence of the increased responsibility towards family duties and reduced income due to the forced interruption of his job. Research indicates the correlation between social deprivation and mania, depression, paranoia and hallucinations via the induction of stress which, then, triggers the psychiatric symptoms (Wickham 2014). Another person who never had contact with psychiatric services developed a full-blown psychotic episode with vivid visual hallucinations. Organic causes for her presentation were excluded. In this case, research suggests the presence of (pseudo)hallucinations in cases of extreme anxiety and conversion disorders (Wearne 2017). It is also reported that subjects high on anxiety scores show more uncertainty about the processing of their sensorial experiences hence being more prone to experience visual and auditory hallucinations under extreme anxiety (García-Montes 2006). Another case presented with an acute manic episode which is incorporated into the COVID-19 generalised concern and misinterpretation. It is reported that early life experiences could have a kindling effect in triggering a bipo- lar disorder in susceptible individuals (Shapero 2017). Besides, important and repeated life events can trigger the occurrence of bipolar disorders (Simhandl 2015).

\section{CONCLUSIONS}

The present study supports the findings of other researchers that COVID-19 pandemic is already having a significant impact on the mental health aspects of the whole population. As in the cases explored, people are scared, concerned, depressed, and discouraged about their national leaders; besides, there is the risk that domestic and interactional terrorist can use COVID-19 pandemic for their terrorist acts (Jakovljevic et al. 2020). It is predicted an upsurge of psychiatric illness linked to the emotional impact of COVID-19 and an increase in the number of persons in need of psychiatric intervention due to COVID-19 pandemic related to anxiety about the ambiguity of the pandemic, facing death in close relatives and friends, reduced financial assets for loss of a job, extreme deviations from routines, isolation and separation from family and beloved ones (Marčinko et al. 2020). Similarly, also those who work for the health-care are emotionally affected, feel anxious about being infected of are already experiencing bereavement (Marčinko et al. 2020). The psychiatric impact will generate a shortage of psychiatrists or services offered on the territory. Such a scenario is already inglobating new technological solutions such as telepsychiatry, online services using the Internet (Ćosić et al. 2020) to share information within teams or to assess patients in the community by using tools such as WhatsApp, Skype, Microsoft Team, or other distance technology. In our psychiatric wards, we started to have virtual ward rounds as multidisciplinary team meetings do not allow social distance while a big screen (linked to a laptop) with video conference liaises several professionals mostly if they work in the community or cannot attend physically. We have already difficulties in deciding the legality of sectioning patients for compulsory treatment 'by distance'. Other authors report that technology of distance psychiatry might create difficulties in confidentiality for data, privacy and data protection (Fagiolini et al. 2020). As also seen in the current study, people already suffering from mental illness will be more susceptible to COVID-19 pandemic with a deterioration of existing conditions due to vulnerability to stress but also due to regulations to reduce attendance to community psychiatric services and difficulties in obtaining prescribed medication (Yao et al. 2020). As hypothesized in the current article, there are initial reports that COVID-19 affects the CNS and the virus has been found in the cerebrospinal fluid, similarly other research reports that about $40 \%$ of patients affected also have neurological symptoms (Baig et al. 2020). As COVID-19 is a social illness as well, there are vulnerable people at risk for the combined impact of the pandemic on the physical and mental health such the homeless, people with debilities, persons with chronic illnesses, and those 
who are institutionalized in prison or other institutions (Kelly 2020). As we illustrated, COVID-19 pandemic is a social illness. It is affecting our way of socializing and halted our freedom of making personal choices in our lives, such as attending to school, social events, concerts, and others (Jakovljevic 2020). The role of psychiatry in these forthcoming months will become central in our lives to allow the global population to cope with this unprecedented and dramatic pandemic.

\section{Acknowledgements: None.}

\section{Conflict of interest: None to declare.}

\section{Contribution of individual authors:}

Carlo Lazzari: concept and design of article, literature searches, writing manuscript, approval of final version.

Ahmed Shoka, Abdul Nusair \& Marco Rabottini: comments on the concept of article, literature searches, writing some parts of manuscript, approval of the final version.

\section{References}

1. Andrews $G$, Tennant $C$ : Life event stress and psychiatric illness. Psychological Medicine 1978; 8:545-549

2. Anon 2020: Italian nurse Daniela Trezzi commits suicide over fears of spreading coronavirus [Internet]. 2020 Alarabiya [cited 4 April 2020]. Available from:

https://english.alarabiya.net/en/features/2020/03/29/Italiannurse-commits-suicide-over-fears-of-spreading-coronavirus

3. Armitage R, Nellums L: COVID-19 and the consequences of isolating the elderly. The Lancet Public Health, 2020

4. Baig A, Khaleeq A, Ali U, Syeda H: Evidence of the COVID-19 Virus Targeting the CNS: Tissue Distribution, Host-Virus Interaction, and Proposed Neurotropic Mechanisms. ACS Chemical Neuroscience 2020; 11:995-998

5. Blum J, Pfeifer S, Hatz C: Psychiatric manifestations as the leading symptom in an expatriate with dengue fever. Infection 2010; 38:341-343

6. Brundin L, Bryleva E. Thirtamara Rajamani K: Role of Inflammation in Suicide: From Mechanisms to Treatment. Neuropsychopharmacology 2016; 42:271-283

7. Courtin E, Knapp M: Social isolation, loneliness and health in old age: a scoping review. Health \& Social Care in the Community 2015; 25:799-812

8. Cunningham A: Epidemics, Pandemics, and the Doomsday Scenario. Historically Speaking 2008; 9:29-31

9. Ćosić K, Popović S, Śarlija M, Kesedžić I: Impact of Human Disasters and COVID-19 Pandemic on Mental Health: Potential of Digital Psychiatry. Psychiatr Danub 2020; 32:25-31

10. Declercq F, Meganck R, Audenaert K: A Case Study of Paternal Filicide-Suicide: Personality Disorder, Motives, and Victim Choice. The Journal of Psychology 2016; 151:36-48

11. Duan L, Zhu G. Psychological interventions for people affected by the COVID-19 epidemic. The Lancet Psychiatry 2020; 7:300-302
12. Fagiolini A, Cuomo A, Frank E: COVID-19 Diary From a Psychiatry Department in Italy. The Journal of Clinical Psychiatry 2020; 81

13. García-Montes J, Cangas A, Pérez-Álvarez M, Fidalgo Á, Gutiérrez O: The role of meta-cognitions and thought control techniques in predisposition to auditory and visual hallucinations. British Journal of Clinical Psychology 2006; 45:309-317

14. Gellatly R, Beck A: Catastrophic Thinking: A Transdiagnostic Process Across Psychiatric Disorders. Cognitive Therapy and Research 2016; 40:441-452

15. Grasselli G, Pesenti A, Cecconi M: Critical Care Utilization for the COVID-19 Outbreak in Lombardy, Italy. JAMA 2020

16. Gyasi R, Yeboah A, Mensah C, Ouedraogo R, Addae E: Neighborhood, social isolation and mental health outcome among older people in Ghana. Journal of Affective Disorders 2019; 259:154-163

17. Ho CS, Chee CY, Ho RC: Mental Health Strategies to Combat the Psychological Impact of COVID-19 Beyond Paranoia and Panic. Annals of the Academy of Medicine, Singapore 2020; 49:1. [Online First]

18. Humble M: Vitamin D, light and mental health. Journal of Photochemistry and Photobiology B: Biology. 2010; 101:142-149

19. Jakovljevic M, Bjedov S, Jaksic N, Jakovljevic I: Covid-19 Pandemia and Public and Global Mental Health from the Perspective of Global Health Security. Psychiatr Danub 2020; 32:6-14

20. Jakovljevic M: Covid-19 Crisis as a Collective Hero's Journay to Better Public and Global Mental Health. Psychiatr Danub 2020; 32:3-5

21. Kang L. et al.: The mental health of medical workers in Wuham, China dealing with the 2019 novel coronavirus. The Lance Psychiatry 2020; 7:e14

22. Kelly B: Covid-19 (Coronavirus): Challenges for Psychiatry. The British Journal of Psychiatry 2020; 1-6

23. Kepińska A, Iyegbe C, Vernon A, Yolken R, Murray R, Pollak T: Schizophrenia and Influenza at the Centenary of the 1918-1919 Spanish Influenza Pandemic: Mechanisms of Psychosis Risk. Frontiers in Psychiatry 2020; 11:1-19

24. Kinney JW, Bemiller SM, Murtishaw AS, Leisgang AM, Salazar AM, Lamb BT: Inflammation as a central mechanism in Alzheimer's disease. Alzheimers Dement 2018; 4:575-590

25. Lai J, Ma S, Wang Y, Cai Z, Hu J, Wei N, et al.: Factors Associated with Mental Health Outcomes Among Health Care Workers Exposed to Coronavirus Disease 2019. JAMA 2020

26. Lazzari C, Costigliola P, Di Bari MA, De Ronchi, D, Volterra V, Chiodo F: AIDS has an increasing diffusion within the heterosexual population. AIDS Patient Care 1994; 8:106-107

27. Lazzari C, Costigliola, P: Sex and AIDS: Can we stop sexual transmission of AIDS? [Sesso e AIDS: Si puo, arrestare la trasmissione sessuale dell'AIDS?]. Bologna: Pitagora Editrice, 1993 [It]

28. Lazzari C, Di Bari MA, Costigliola P, De Ronchi D, Volterra V, Chiodo F: Deliberate HIV infections, a way of committing suicide. The Italian Journal of Suicidology [Giornale Italiano di Suicidologia] 1993; 1:4-15

29. Lazzari C, Gandolfi Colleoni G, Trallo F: Eros, Sexual Illnesses, Society [Eros, Malattie Sessuali, Societa']. Bologna: Pitagora Editrice, 1996 [It] 
30. Lazzari C, Rajanna T, Nusair A, Rance T: The first presentation of dementia with psychosis after a systemic inflammation: a neurophysiological explanation. Proc Physiol Soc 2019; 43:PC211. Available from: https://www.physoc.org/abstracts/the-first-presentationof-dementia-with-psychosis-after-a-systemicinflammation-a-neurophysiological-explanation/

31. Lazzari C: La Sindrome di Samo. Rivista di Sessuologia Clinica 2013; 1:53-72

32. Lazzari C, Masino M: Psychology and Philosophy of Health [Psicologia e Filosofia della Salute]. Milan: Libreriauniversitaria. It Editor, 2015 [It]

33. Liebrenz M, Bhugra D, Buadze A, Schleifer R: Caring for persons in detentions with mental illness during Coivd-19 outbreak. Forensic Science International: Mind and Law 2020 [ahead of print]

34. Makwana N: Disaster and its impact on mental health: $A$ narrative review. Journal of Family Medicine and Primary Care 2019; 8:3090

35. Mancinelli I, Comparelli A, Girardi P, Tatarelli R: Mass Suicide: Historical and Psychodynamic Considerations. Suicide and Life-Threatening Behavior 2002; 32:91-100

36. Marčinko D, Jakovljević M, Jakšić N, Bjedov S, Mindoljevic Drakulić A: The Importance of Psychodynamic Approach During COVID-19 Pandemic. Psychiatr Danub 2020; 32:15-21

37. Paykel E: Contribution of life events to causation of psychiatric illness. Psychological Medicine 1978; 8:245-253

38. Perry S, Jacobsen P: Neuropsychiatric Manifestations of AIDS-Spectrum Disorders. Psychiatric Services 1986; 37:135-142

39. Prochaska J, DiClemente C: Transtheoretical therapy: Toward a more integrative model of change. Psychotherapy: Theory, Research \& Practice 1982; 19:276-288

40. Public Health England: Total UK COVID-19 Cases Update. ArcGIS Dashboards [Internet]. Arcgis.com. 2020 [cited 4 April 2020]. Available from: https://www.arcgis.com/apps/opsdashboard/index.html\#/f 94c3c90da5b4e9f9a0b19484dd4bb14https://www.arcgis.c om/apps/opsdashboard/index.html\#/f94c3c90da5b4e9f9a0 b19484dd4bb14

41. Report W: COVID-19: Man commits suicide over coronavirus scare [Internet]. MSN. 2020 [cited 4 April 2020]. Available from: https://www.msn.com/en-ae/news/world/ COVID-19-man-commits-suicide-over-coronavirusscare/ar-BBZUrTu

42. Rosenstock I, Strecher V, Becker M: Social Learning Theory and the Health Belief Model. Health Education Quarterly 1988; 15:175-183

43. Royal College of Psychiatrists: COVID-19: Ethical considerations [Internet]. Royal College of Psychiatrists. 2020 [cited 7 April 2020]. Available from: https://www.rcpsych.ac.uk/about-us/responding-toCOVID-19/responding-to-COVID-19-guidance-forclinicians/COVID-19-ethical-considerations
44. Saleva O, Putkonen H, Kiviruusu O, Lönnqvist J: Homicide-suicide - An event hard to prevent and separate from homicide or suicide. Forensic Science International 2007; 166:204-208

45. Sen P, Chowdhury A: Culture, ethnicity, and paranoia. Current Psychiatry Reports 2006; 8:174-178

46. Shalev D, Shapiro P: Epidemic psychiatry: The opportunities and challenges of COVID-19. General Hospital Psychiatry 2020. [ahead online publication]

47. Shapero B, Weiss R, Burke T, Boland E, Abramson L, Alloy L: Kindling of Life Stress in Bipolar Disorder: Effects of Early Adversity. Behavior Therapy 2017; 48:322-334

48. Simhandl C, Radua J, König B, Amann B: The prevalence and effect of life events in 222 bipolar I and II patients: A prospective, naturalistic 4-year follow-up study. Journal of Affective Disorders 2015; 170:166-171

49. Soliman A, O'Driscoll G, Pruessner J, Holahan A, Boileau I, Gagnon D et al.: Stress-Induced Dopamine Release in Humans at Risk of Psychosis: a [11C] Raclopride PET Study. Neuropsychopharmacology 2007; 33:2033-2041

50. Tidman Z: Coronavirus: Italian man 'kills girlfriend after wrongly accusing her of infecting him'. 2020. Available at: https://www.msn.com/en-nz/news/world/coronavirusitalian-man-kills-girlfriend-after-wrongly-accusing-herof-infecting-him/arBB127ZoX? li $=$ BBqdg4K\&fbclid $=I w A R 2 Z U A D F K 68 r f n I I$ UzPQiD0V7ehJs-a0wlhm0GcpXcJKyvNfuwRAbxgqCCk

51. Torjesen I: Admission for infection is linked to increased suicide risk. BMJ 2016; i4416

52. Wearne D, Curtis GJ, Genetti A, Samuel M, Sebastian J: Where pseudo-hallucinations meet dissociation: a cluster analysis. Australasian Psychiatry 2017; 25:364-368

53. Wickham S, Taylor P, Shevlin M, Bentall R: The Impact of Social Deprivation on Paranoia, Hallucinations, Mania and Depression: The Role of Discrimination Social Support, Stress and Trust. PLoS ONE 2014; 9:e105140

54. World Health Organization: The ICD-10 Classification of Mental and Behavioural Disorders. Geneve: WHO. Available from:

https://www.who.int/classifications/icd/en/GRNBOOK.pdf

55. Xiang YT, Yang Y, Li W, Zhang L, Zhang $Q$, Cheung T, Ng CH: Timely mental health care for the 2019 novel coronavirus outbreak is urgently needed. The Lancet Psychiatry 2020; 7:228-229

56. Yang $Y$, Li W, Zhang $Q$, Zhang L, Cheung T, Xiang $Y$ : Mental health services for older adults in China during the COVID-19 outbreak. The Lancet Psychiatry 2020; 7:e19

57. Yao H, Chen J, Xu Y: Patients with mental health disorders in the COVID-19 epidemic. The Lancet Psychiatry 2020; $7: e 21$

58. Zigmond T, Brindle N: A clinician's brief guide to the Mental Health Act. $4^{\text {th }}$ ed., Cambridge: Cambridge University Press, 2016

Correspondence:

Carlo Lazzari, $M D$

South-West Yorkshire NHS Trust, Fieldhead Hospital

Wakefield, United Kingdom

E-mail: carlolazzari@nhs.net 